\title{
Perfil hematológico e bioquímico plasmático de camundongos após ingestão da planta Arrabidaea chica
}

Profile hematological and biochemical of mice plasma after intake of plant Arrabidaea chica

\author{
FERREIRA, F. A. G. ${ }^{1 *}$; SILVA, F. C. ${ }^{2}$; CARVALHO, C. M. ${ }^{3}$; COSTA, \\ J.C. ${ }^{3}$; FERREIRA, J. M. R. ${ }^{3}$
}

${ }^{1}$ Departamento de Métodos e Técnicas de Ensino/Faculdade de Educação/ Universidade do Estado de Minas Gerais, Minas Gerais, CEP 30130140, Belo Horizonte - Minas Gerais, Brasil.

${ }^{2}$ Departamento de Química/Unidade Divinópolis/ Universidade do Estado de Minas Gerais, Minas Gerais, CEP 35501170, Divinópolis - Minas Gerais, Brasil.

${ }^{3}$ Departamento de Química/Núcleo de Estudos de Plantas Medicinais/Universidade Federal de Minas Gerais, CEP 31270901, Belo Horizonte - Minas Gerais, Brasil.

\author{
*biologaguedes@gmail.com
}

(Recebido em 25 de janeiro de 2016; aceito em 19 de agosto de 2016)

\begin{abstract}
A planta Arrabidaea chica (Humb. \& Bonpl.) B. Verl. (família Bignoniaceae), chamada popularmente de pariri, é uma planta nativa das florestas tropicais conhecida pelo seu amplo uso na medicina popular. $\mathrm{O}$ objetivo deste estudo foi verificar a ação de A. chica sobre os parâmetros hematológicos e bioquímicos plasmáticos de camundongos $(\mathrm{n}=24)$ Swiss (Mus musculus) através do uso contínuo (ad libitum), durante 45 dias, de extratos aquoso e etanólico das folhas de A. chica. Ao fim do teste, foi feita uma avaliação clínica das condições físicas e a massa corporal dos camundongos, após o sangue dos animais foram coletados por punção cardíaca. Os resultados mostraram que o extrato foliar etanólico foi mais eficiente, apresentando aumento $(\mathrm{p}<0,05)$ de $9,2 \%$ na concentração de hemácias, $36,1 \%$ na concentração de leucócitos e 29,5\% na concentração de plaquetas. Quanto ao perfil bioquímico plasmático, os camundongos apresentaram aumento $(\mathrm{p}<0,05)$ das enzimas fosfatase alcalina e aspartato transaminase indicando hepatoxicidade. Os resultados indicam A. chica como uma candidata à exploração pela indústria farmacêutica, devido ao seu potencial fitoterápico contra doenças que debilitam parâmetros hematológicos, principalmente no que tange a deficiência plaquetária.
\end{abstract}

Palavras-chave: Arrabidaea chica, hematologia, camundongo.

The plant Arrabidaea chica (Humb. \& Bonpl.) B. Verl. (Bignoniaceae), known as pariri is a native plant of tropical forests and known for its widespread use in folk medicine. The objective of this study was to investigate the action of A. chica in increased hematological and biochemical parameters plasma of mice $(\mathrm{n}=24)$ Swiss (Mus musculus) through continuous use (ad libitum), for 45 days, of water extracts and ethanol the leaves of A. chica. At the end of the test, a clinical evaluation to assess physical condition and body weight of the mice, was made after the blood of animals were collected by cardiac puncture. The results showed the ethanol extract was more efficient than the aqueous extract, an increase $(\mathrm{p}<0.05)$ of $9.2 \%$ in the concentration of red blood cells, $36.1 \%$ in white blood cells concentration and $29.5 \%$ in the concentration of platelets. As for plasma biochemical profile, the mice showed an increase $(\mathrm{p}<0.05)$ of the enzymes alkaline phosphatase and aspartate transaminase indicating hepatotoxicity. A. Chica has potential for exploitation in the pharmaceutical industry, because of its herbal medicine against diseases that debilitate hematological parameters, particularly in regard to platelet deficiency.

Keywords: Arrabidaea chica, hematology, mice.

\section{INTRODUÇÃO}

A flora amazônica é considerada a maior reserva de biodiversidade do planeta, com poucas espécies de plantas estudadas cientificamente [1]. A espécie Arrabidaea chica (Humb. \& Bonpl.) B. Verl., é nativa das florestas tropicais sendo encontrada na América Central e em toda a Amazônia. É conhecida popularmente como crajiru, carajuru, pariri, cipó cruz, coá-pyranga, guajuru, gujuru-piranga, oajuru, ou pyranga [2]. Pertence à família das Bignoniaceaes, conhecida 
como família do Ipê, que contém 120 gêneros com aproximadamente 800 espécies, as quais em sua maior parte, nas regiões tropicais e subtropicais [3].

A. chica é uma planta medicinal usada como anti-inflamatória, cicatrizante, antianêmica e para tratar cólicas intestinais, hemorragia, diarreia, leucorreia e leucemia $[2,4,5]$. Também usada como agente adstringente, sendo seu extrato usado na cosmética em forma de sabonete cremoso produzindo efeito antiacne [6] e antifúngico [5]. A tintura extraída das folhas da planta é usada para tratar infecções cutâneas e doenças ginecológicas [7]. A planta é preparada na forma de chá, através do decocto das folhas [8].

Estudos químicos relatam o isolamento de fitosteroides, flavonoides e pigmentos utilizados em cosméticos como: carajurona, carajurina e 3-desoxiantocianidinas [2]. As propriedades responsáveis pela cor avermelhada do extrato de A. chica deriva dos pigmentos flavônicos encontrados nas folhas da planta $[9,10]$. Testes de toxicidade aguda indicaram que a DL50 de $A$. chica em camundongos, ultrapassa $2 \mathrm{~g} / \mathrm{kg}$ i.p. e $6 \mathrm{~g} / \mathrm{kg}$ v.o., sugerindo baixa toxicidade [1].

Na medicina popular $A$. chica é uma espécie vegetal muito utilizada, no modo de chá, como aliada no tratamento de câncer sendo considerada uma precursora no aumento de células sanguíneas. O câncer tem sido uma das maiores causas de mortalidade no mundo [11]. Pessoas com esta doença são geralmente destinadas aos tratamentos de quimioterapia e/ou radioterapia, o que pode levar a um quadro anêmico, uma vez que durante estes tratamentos o paciente sofre drásticas reduções nas células do sangue. Tais diminuições nos parâmetros hematológicos geralmente inviabiliza a continuidade do tratamento e maximiza as complicações relacionadas ao câncer [12].

Por estas razões A. chica é comumente usada por pessoas com câncer, devido ao crescente conhecimento popular de que a espécie aumenta a concentração, principalmente, de hemácias e plaquetas durante o tratamento de quimioterapia e/ou radioterapia. Conveniente à importância deste fato, surgiu o objetivo de verificar ação desta planta, na forma de extrato, para o aumento de parâmetros hematológicos e bioquímicos de camundongos Swiss (Mus musculus) de modo a verificar a possibilidade da espécie em atuar como auxiliar fitoterápico durante o tratamento de doenças que debilitam parâmetros hematológicos.

\section{MATERIAL E MÉTODOS}

As folhas de Arrabidaea chica foram coletadas no distrito de Azurita, Mateus Leme, Minas Gerais, Brasil (-19.9985101, -44.4087348) durante o ano de 2013. A planta foi identificada na Universidade de Campinas, São Paulo, Brasil. Uma exsicata se encontra depositada no herbário da referida Universidade sob o número UEC 145.956.

Folhas de A. chica foram secas em temperatura ambiente, e moídas em moinho de facas. Posteriormente, foram submetidas a técnicas de extração e fracionamento [11] para obtenção do extrato etanólico (EE) e extrato aquoso (EA) de A. chica. Utilizou-se etanol PA 99\%, marca Synth, Brasil, para o EE e água destilada para o EA. Os extratos finais foram liofilizados e armazenados para uso diário durante os testes.

Para experimentação foram utilizados 24 camundongos, Swiss machos da espécie Mus musculus pesando entre 22 e $25 \mathrm{~g}$, provenientes do Biotério da Universidade Federal de Minas Gerais (UFMG). Inicialmente os camundongos passaram por um período de adaptação às condições ambientais do laboratório com fornecimento de água e alimento.

Após adaptação, os 24 animais foram divididos em três grupos $(\mathrm{n}=8$ cada) e tratados por 45 dias com água destilada (Grupo Controle), extrato aquoso (Grupo Aquoso) e extrato etanólico (Grupo Etanólico). Todos animais foram mantidos em gaiolas de polipropileno "mouse pack", sob temperatura controlada entre 22 e $25^{\circ} \mathrm{C}$, recebendo água e ração apropriada "ad libitum", e iluminação controlada com ciclo de 12 horas.

Diariamente, o extrato aquoso e o extrato etanólico (30 mg/kg massa corporal) foram diluídos em água destilada (300 ml) e colocados na mamadeira dos animais. A seleção das doses diárias foi baseada na pesquisa de Ribeiro et al (2012) [11] que estudou as propriedades de A. chica em camundongos da espécie Mus musculus. Ao grupo controle foi oferecido diariamente $300 \mathrm{ml} \mathrm{de}$ água destilada. 
Ao final do experimento os animais foram anestesiados com cetamina (50 mg. $\left.\mathrm{g}^{-1}\right)$ e xilazina $(20 \mathrm{mg} / \mathrm{kg}$ ) para coleta imediata de sangue por punção cardíaca. Utilizou-se EDTA a 10\% como anticoagulante.

Utilizou-se um hemocitômetro (CELM DA 500®, Barueri-SP, Brasil) para estimar os seguintes parâmetros hematológicos: eritrócitos, hematócrito, hemoglobina, volume corpuscular médio, hemoglobina corpuscular média e concentração de hemoglobina corpuscular média. Para os leucócitos, os parâmetros analisados foram: contagem total de leucócitos, e diferencial (neutrófilos, eosinófilos, basófilos, linfócitos e monócitos).

Posteriormente, o sangue foi centrifugado para obtenção de plasma utilizado para as provas bioquímicas, conforme Ribeiro (2012) [11].

Todo o protocolo experimental desenvolvido neste estudo foi primeiramente submetido ao Comitê de Ética da Universidade Federal de Minas Gerais (UFMG) IACUC protocolo $\mathrm{n}^{\circ}$ 155/2009.

Para análise estatística todos os dados foram verificados quanto à normalidade. A significância estatística entre grupos foi realizada através da aplicação de uma análise de variância ANOVA one-way para comparar a concentração de células sanguíneas nos diferentes grupos, seguido pelo teste de Student-Newman-Keuls (SNK) ou de Duncan quando os dados de teste foram distribuídos normalmente. Kruskal-Wallis ou Mann-Whitney U foram utilizados quando os dados não foram distribuídos normalmente. Sendo admitido $\mathrm{p}<0,05$ como erro padrão. Os dados foram expressos em MÉDIA \pm DP.

\section{RESULTADOS E DISCUSSÃO}

\subsection{Ingestão diária dos extratos de A. chica e de água pelos camundongos}

Os camundongos de cada grupo ingeriram, em média, $72,8 \mathrm{ml}$ por dia de extrato aquoso, etanólico e água destilada, não havendo diferença entre os grupos (p>0,05). Todos os camundongos permaneceram ativos, com boas condições físicas e comportamento típico da espécie. Ao final do teste apresentaram, em média, 42,8 gramas não havendo diferença entre os animais controle e tratamentos.

\subsection{Perfil hematológico}

No que se refere à hematologia, os extratos de A. chica ocasionaram aumento na concentração dos principais parâmetros sanguíneos testados, sendo mais expressivas as alterações ocasionadas pelo extrato etanólico.

A concentração de hemácias nos camundongos tratados com extrato etanólico de A. chica foi maior em relação ao grupo controle $(9,2 \% ; \mathrm{p}<0,05)$. Porém, nos camundongos que ingeriram extrato aquoso não houve diferença significativa $(3,7 \%$; $>0,05)$ (Figura 1).

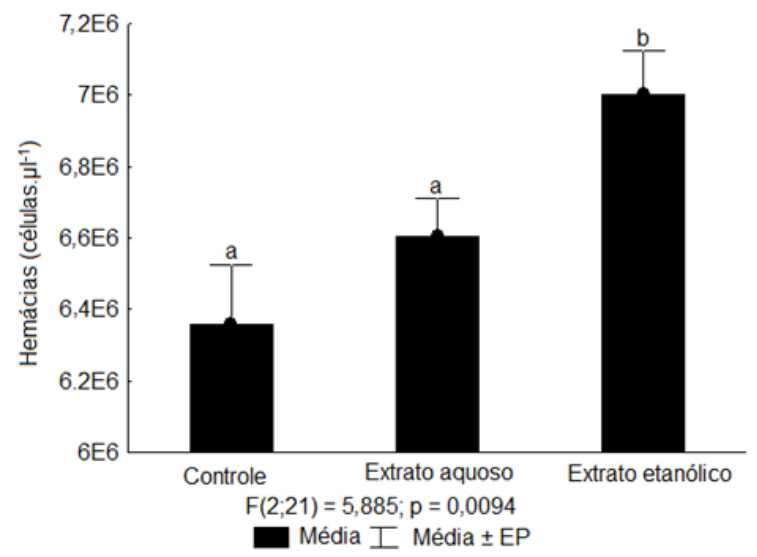

Figura 1: Hemácias nos tratamentos controle (água destilada), extrato aquoso e extrato etanólico, após 45 dias de teste. Anova One way: letras iguais representam valores não significativos $(p>0,05)$, letras diferentes valores significativos ( $p<0,05)$. 
Os índices anisocítico das hemácias não apresentaram variação significativa em nenhum dos tratamentos, porém ocorreram diminuições significativas $(\mathrm{p}<0,05)$ no volume corpuscular médio (VCM) das hemácias nos dois grupos tratamento. Não houve diferença $(p>0,05)$ na concentração de hemoglobina (Tabela 1).

Tabela 1: Parâmetros hematológicos testados nos camundongos após 45 dias de ingestão de água destilada (Controle) extrato aquoso (EA) e extrato etanólico (EE) de A. chica. Expressos em Média \pm Desvio padrão. (*) Representa valores significativos $p<0,05$.

\begin{tabular}{|c|c|c|c|}
\hline Parâmetros & Controle & EA & $\mathbf{E E}$ \\
\hline Hemácias (cél. x10\%/ $\mu \mathrm{L}$ ) & $6,3 \pm 0,5$ & $6,6 \pm 0,3$ & $7,0 \pm 0,3^{*}$ \\
\hline Índice anisocítico das hemácias (\%) & $16,2 \pm 2,0$ & $14,9 \pm 1,2$ & $15,9 \pm 0,9$ \\
\hline Hematócritos (\%) & $39,2 \pm 2,7$ & $36,1 \pm 2,8$ & $39,2 \pm 1,4$ \\
\hline Hemoglobina (g/dL) & $11,7 \pm 1,0$ & $11,2 \pm 1,0$ & $12,3 \pm 0,6$ \\
\hline VCM (fL) & $58,2 \pm 1,2$ & $55,9 \pm 1,3^{*}$ & $57,1 \pm 0,7 *$ \\
\hline HCM (pg) & $17,4 \pm 0,4$ & $17,4 \pm 0,4$ & $17,8 \pm 0,6$ \\
\hline $\mathrm{CHCM}(\mathrm{g} / \mathrm{dL})$ & $29,9 \pm 0,8$ & $31,1 \pm 0,5^{*}$ & $29,7 \pm 5,2$ \\
\hline Plaquetas (cél. x 103/ $\mu \mathrm{L}$ ) & $580,4 \pm 278,8$ & $762,0 \pm 140,8$ & $823,5 \pm 71,6^{*}$ \\
\hline Índice anisocítico de Plaquetas (\%) & $4,9 \pm 4,6$ & $3,2 \pm 0,4$ & $3,7 \pm 1,6$ \\
\hline Leucócitos (cél. x 103/ $\mu \mathrm{L}$ ) & $2,2 \pm 0,5$ & $2,4 \pm 1,5$ & $3,4 \pm 1,3^{*}$ \\
\hline Linfócitos (\%) & $79,9 \pm 4,2$ & $80,1 \pm 7,1$ & $75,6 \pm 3,4^{*}$ \\
\hline $\begin{array}{c}\text { Neutrófilos, monócitos e } \\
\text { basófilos }(\%)\end{array}$ & $18,9 \pm 4,1$ & $18,0 \pm 6,9$ & $22,4 \pm 3,4^{*}$ \\
\hline Eosinófilos (\%) & $1,1 \pm 0,9$ & $1,9 \pm 1,1$ & $2,0 \pm 1,5$ \\
\hline
\end{tabular}

VCM (Volume Corpuscular Médio); HCM (Hemoglobina Corpuscular Média); CHCM (Concentração de Hemoglobina Corpuscular Média).

O extrato etanólico aumentou 29,9\% (p<0,05) a concentração de plaquetas dos camundongos (Figura 2).

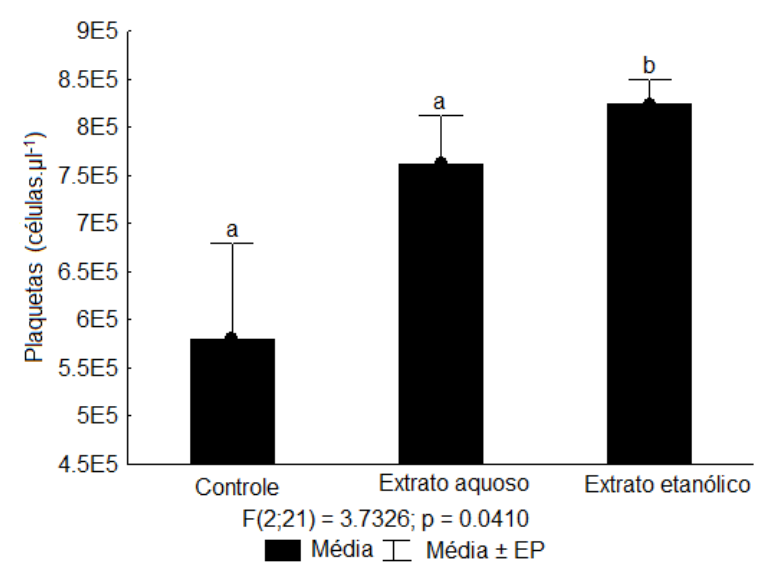

Figura 2: Plaquetas nos tratamentos controle (água destilada), extrato aquoso e extrato etanólico, após 45 dias de teste. Anova One way: letras iguais representam valores não significativos ( $p>0,05)$, letras diferentes valores significativos $(p<0,05)$.

Os resultados hematológicos mostraram que A. chica ocasiona aumento significativo nos principais parâmetros sanguíneos testados (hemácias, VCM, CHCM, plaquetas, Leucócitos totais, linfócitos, neutrófilos, monócitos e basófilos) principalmente quando as propriedades das folhas da planta são extraídas com solvente etanólico.

O aumento expressivo da concentração de plaquetas $(29,9 \% ; \mathrm{p}<0,05$ para EE) pode ser devido à alta concentração de ferro $(115,5 \mu \mathrm{g} / \mathrm{g})$ encontrada nas folhas da planta [14]. Figueira et al. (2010) [15], também ao analisar o perfil hematológico de camundongos, após ingestão das folhas de A. chica preparadas como chá, percebeu que este aumentou significativamente a concentração 
de plaquetas, hemoglobina corpuscular e hemácias, corroborando com muitos dos resultados deste presente estudo, que ao invés do chá usou extratos das folhas de A. chica.

\subsection{Perfil bioquímico}

Quanto aos parâmetros bioquímicos, não houve diferença significativa entre as concentrações de proteínas totais nos tratamentos com A. chica comparados ao controle (Figura 3).

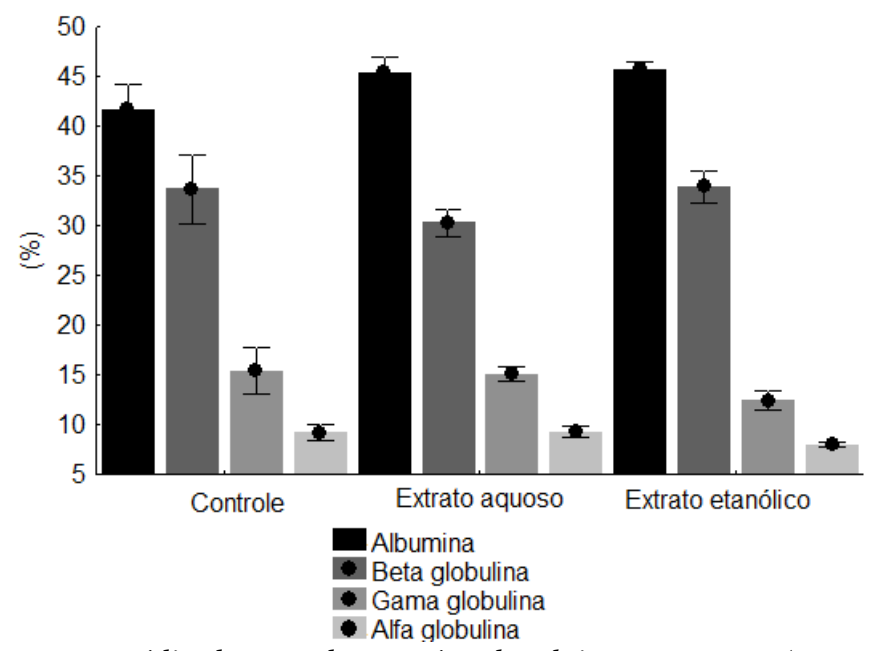

Figura 3: Comparação média da taxa de proteína dos dois tratamentos (extrato aquoso e extrato etanólico) com o controle, após 45 dias de tratamento. Total das proteínas é igual a 100\%.

O perfil bioquímico plasmático dos animais manteve-se dentro dos valores de referência [16] com exceção da Enzima Fosfatase Alcalina (FAL) e Aspartato transaminase (AST) (Tabela 2).

Tabela 2: Resultado dos parâmetros bioquímicos plasmáticos. Expressos em Média \pm Desvio padrão. (*) Representa valores significativos $p<0,05$ em relação ao controle.

\begin{tabular}{clll}
\hline Parâmetros bioquímicos & Controle & Extrato aquoso & $\begin{array}{l}\text { Extrato } \\
\text { etanólico }\end{array}$ \\
\hline Aspartato transaminase (AST) (U/L) & $34,3 \pm 6,7$ & $72,8 \pm 39,3^{*}$ & $52,2 \pm 19,9^{*}$ \\
Fosfatase alcalina (FAL) (U/L) & $113,9 \pm 31,93$ & $168,6 \pm 43,4^{*}$ & $217,7 \pm 19,6^{*}$ \\
Uréia (mg/dL) & $60,9 \pm 13,0$ & $70,9 \pm 16,9$ & $62,1 \pm 10,5$ \\
Creatinina (mg/dL) & $0,39 \pm 0,03$ & $0,35 \pm 0,12$ & $0,36 \pm 0,12$ \\
\hline
\end{tabular}

Alterações bioquímicas das proteínas séricas como a AST e a FAL, conforme se observou na tabela 2, indicam hepatoxicidade [17]. Conforme Oliveira et al (2008)[1] a toxicidade aguda de $A$. chica é de $6 \mathrm{~g} / \mathrm{kg}$ por via oral, porém a toxicidade crônica, conforme Sousa et al (2009)[18]em concentrações entre 0,25 e $1,25 \mathrm{mg} / \mathrm{ml}$ de extrato hidroalcoólico, apresenta efeitos tóxicos no que se refere ao metabolismo energético. Assim, este aumento $(\mathrm{p}<0,05)$ das enzimas FAL e AST nos camundongos tratados com A. chica indicam possíveis lesões nos ductos biliares, uma vez que as mesmas são enzimas presentes nas células que delineiam os ductos biliares do fígado e que quando estes estão lesados liberam estas enzimas para o plasma sanguíneo.

É importante ressaltar que enquanto a enzima FAL é comumente relacionada a lesões nos ductos biliares a enzima AST é relacionada a lesões nos fígado, ainda que podendo ser proveniente de outros órgãos tais como o coração, músculos e ossos [19]. $O$ aumento $(p<0,05)$ de FAL e AST no sangue dos animais tratados com A. chica indica que esta planta pode ocasionar lesões hepáticas. Porém, tais lesões possuem menor incidência em seres humanos, uma vez que estes ingerem $A$. chica em concentrações e volumes muito mais reduzidos, o que diminui a possibilidade de se observar a ocorrência de toxidade aguda hepática. Por outro lado, conforme Neto et al.(1998)[20] e Chang et al. (2000)[21] A. chica é contraindicada à pacientes portadores de nefropatias. Porém, propriedades medicinais diversas são consideradas à A. chica $[1,4,5,22$, $23,24]$. 
A ureia e a creatinina são provas de função renal e consequentemente cardíaca, devido ao processo de filtragem sanguínea. Neste estudo, tanto a ureia quanto a creatinina dos camundongos tratados com os extratos de A. chica mantiveram-se, em relação aos animais controle, dentro do padrão de referência para camundongos [25]. Tal resultado pode indicar que A. chica não ocasiona toxicidade renal em camundongos.

\section{CONCLUSÃO}

A ingestão oral, por 45 dias, de extrato aquoso e etanólico produzido a partir das folhas da planta A. chica aumentam a concentração de parâmetros hematológicos importantes em camundongos (Mus musculus). O extrato foliar etanólico foi mais eficiente, apresentando aumento $(\mathrm{p}<0,05)$ de $9,2 \%$ na concentração de hemácias, $36,1 \%$ na concentração de leucócitos e $29,5 \%$ na concentração de plaquetas. O aumento expressivo na concentração de plaquetas pode ser devido à elevada concentração de ferro existentes nas folhas de A. chica.

O perfil bioquímico plasmático dos camundongos mantiveram-se normais, com exceções das enzimas fosfatase alcalina e aspartato transaminase que aumentaram a concentração $(p<0,05)$, o que pode ser oriundo de alguma toxicidade nos ductos biliares e no fígado dos camundongos.

Portanto, Arrabidaea chica é uma planta candidata a exploração pela indústria farmacêutica como um potencial fitoterápico a ser usado em doenças que debilitam parâmetros hematológicos, principalmente no que tange a deficiência plaquetária.

\section{REFERÊNCIAS BIBLIOGRÁFICAS}

1. Oliveira DPC, Borrás MRL, Ferreira LCL, Lopez-Lozano, JL. Atividade antiinflamatória do extrato aquoso de Arrabidaea chica (Humb. \& Bonpl.) B. Verl. sobre o edema induzido por venenos de serpentes amazônicas. Rev. bras. farmacogn.[on line] 2009 Apr./June; vol.19, n.2b, pp. 643-649, doi.org/10.1590/S0102-695X2009000400024.

2. Zorn B, García-Pineres AJ, Castro V, Murillo R, Mora G, Merfort I. 3 Desoxyanthocyanidins from Arrabidaea chica. Phytochemistry. 2001 Apr; 56(8):831-835, doi: 10.1016/S0031-9422(01)00038-3.

3. Alves MSM, Mendes PC, Vieira JGP, Ozela EF, Barbosa WLR, Silva-Júnior JOC. Análise farmacognóstica das folhas de Arrabidaea chica (Humb. \& Bonpl.) B. Verlt., Bignoniaceae. Rev. bras. farmacogn. 2010 Maio; 20( 2 ): 215-221, doi.org/10.1590/S0102-695X2010000200013.

4. Jorge M P, Madjarof C, Ruiz ALTG, Fernandes AT, Rodrigues RAF, Sousa IMO, Foglio MA, Carvalho JE. Evaluation of wound healing properties of Arrabidaea chica Verlot extract. J Ethnopharmacol. 2008 Aug 13;118(3):361-366. doi: 10.1016/j.jep.2008.04.024.

5. Barbosa WLR, Pinto LN, Quignard E, Vieira JMS, Silva JJOC, Albuquerque S. Arrabidaea chica (HBK) Verlot: phytochemical approach, antifungal and trypanocidal activities. Rev. Bras. Farmacogn. 2008 Dec; 18(4): 544-548, doi: org/10.1590/S0102-695X2008000400008.

6. Takemura OS, Linuma M, Tosa H, Miguel OG, Moreira EA, Nozawa Y. A flavones form leaves of Arrabidaea chica f. cúprea. Phytochemistry. 1995 Mar;38(5):1299-1300, doi:10.1016/00319422(94)00786-S.

7. Grenand P, Moretti C, Jacquemin H. Pharmacopees traditionelles em Guyana. Paris: L'orstom; 1987.457 p.

8. Borrás MRL. Plantas da Amazônia; medicinais ou mágicas?: plantas comercializadas no mercado Municipal Adolpho Lisboa. Manaus; Valer/ Governo do Estado do Amazonas, 2003. 321 p.

9. Chapman E, Perkin AG, Robinson R. CCCCII - The colouring matters of carajura. J Chem Soc. 1927, 3015-3040. Doi: 10.1039/JR9270003015.

10. Ponniah, L., Seshadri, T. R. Nuclear oxidation in flavones and related compounds. Part XLV. A synthesis of carajuridin chloride and carajurin. In Proceedings of the Indian Academy of Sciences, Section: Indian Academy of Sciences. 1953 38(1): 77-83.

11. Ribeiro AFC, Telles TC, Ferraz VP, Souza-Fagundes EM, Cassali GD, Carvalho AT, Melo MM. Effect of Arrabidaea chica extracts on the Ehrlich solid tumor development. Braz. J. Pharmacog. 2012 Apr; 22(2): 364-373, doi.org/10.1590/S0102-695X2011005000225.

12. Ferreira FAG, Carvalho CM, Costa JC, Ferreira JMR, Silva FC. Comprovação do potencial medicinal de Arrabidaea chica (Bignoniaceae). Scientia prima. 2013 Set; 1(1): 15-20.

13. Matos FJA. Introdução a Fitoquímica Experimental. Fortaleza: Editora Letra Livre Editora Ltda; 1988. $150 \mathrm{p}$. 
14. Magalhães IRS, Soares AO, Araújo LM, Costa PRC, Araújo IR, Borrás, MRL. Determination of Cu, $\mathrm{Fe}, \mathrm{Mn}$, and $\mathrm{Zn}$ in the leaves and tea of Arrabidaea chica (Humb. \& Bompl.) Verl. Biol Trace Elem Res. 2009 Dec; 132(1-3): 239-46, doi: 10.1007/s12011-009-8381-2.

15. Figueira GM, Ramelo PR, Ogasawara DC, Montanari JrI, Zucchi MI, Cavallari MM, Foglio MA. A set of microsatellite markers for Arrabidaea chica (Bignoniaceae), a medicinal liana from the neotropics. Am. J. Bot. 2010 July; 97(7):e63-e64, doi:10.3732/ajb.1000145.

16. Harkness JE, Wagner J. Biologia e clínica de roedores. São Paulo: Livraria Roca Ltda. 1993. 250p.

17. Roman SS, Scolari S, Bergamin NA, Sachetti CG. Toxicidade renal e hepática em camundongos prenhes expostos à associação do ácido 2,4 diclorofenoxiacético e do glifosato. Revista Eletrônica de Farmácia, 2009 6(2): 152 - 171, doi: http://dx.doi.org/10.5216/ref.v6i2.6562.

18. Souza AS, Pagadigorria CLS, Ishii-Iwamoto EL, Bracht A, Cortez DAG, Yamamoto NS. Effects of the Arrabidaea chica extract on energy metabolism in the rat liver. Pharmaceutical Biology, 2009 47(2): 154-161, doi: 10.1080/13880200802436281.

19. Medeiros BJL, Costa KS, Ribeiro JFA, Silva JOC, Barbosa WLR, Carvalho JCT. Liver protective activity of a hydroethanolic extract of Arrabidaea chica (Humb. and Bonpl.) B. Verl. (pariri). Pharmacognosy Res. 2011 Apr-Jun; 3(2): 79-84, doi: 10.4103/0974-8490.81954.

20. Neto MM, Robl F, Netto JC. Intoxication by star fruit (Averrhoa carambola) in six dialysis patients? Nephrol. Dial. Transplant. 1998 13(3): 570-572.

21. Chang JM, Hwang S J, Kuo HT, Tsai JC, Guh JY, Chen HC, Tsai JH, Lai YH. 2000. Fatal outcome after ingestion of star fruit (Averrhoa carambola) in uremic patients. Am J Kidney Dis. 2000 Febr; 35(2): 189-193, doi:10.1016/S0272-6386(00)70325-8.

22. Gemelli, TF, Prado LDS, Santos FS, de Souza, AP, Guecheva, TN, Henriques, JAP, Ferraz AB, Corrêa DS, Dihl RR, Picada JN. Evaluation of Safety of Arrabidaea chica Verlot (Bignoniaceae), a Plant with Healing Properties. Journal of Toxicology and Environmental Health. 2015 Part A: 78(18), 11701180,doi:10.1080/15287394.2015.1072070.

23. Sá JC, Almeida-Souza F, Mondêgo-Oliveira R, Silva Oliveira IDS, Lamarck L, Magalhães IDFB, Ataídes-Lima AF, Ferreira Hda S, Abreu-Silva AL. Leishmanicidal, cytotoxicity and wound healing potential of Arrabidaea chica Verlot. BMC Complementary and alternative medicine. 2016: 16(1), 1, doi: 10.1186/s12906-015-0973-0.

24. Aro AA, Simões GF, Esquisatto MAM, Foglio MA, Carvalho JE, Oliveira ALR, Gomes L, Pimentel ER. Arrabidaea chica extract improves gait recovery and changes collagen content during healing of the Achilles tendon. Injury. 2013: 44(7), 884-892, doi:http://dx.doi.org/10.1016/j.injury.2012.08.055

25. Almeida AS, Faleiros ACG, Teixeira DNS, Cota UA, Chica JEL. Valores de referência de parâmetros bioquímicos no sangue de duas linhagens de camundongos. J Bras Patol Med Lab.2008 Dez; 44(6): 429-432, doi.org/10.1590/S1676-24442008000600006. 